\title{
THE USE OF MATH APPS AND THE MATHEMATICS PERFORMANCE OF GRADE 8 STUDENTS IN NEW NORMAL EDUCATION
}

\author{
Ijane Guarte Barrientos
}

\author{
Article DOI: https://doi.org/10.36713/epra7869 \\ DOI No: 10.36713/epra7869
}

\begin{abstract}
This study on the use of math apps and the performance of grade 8 students in Mathematics under new normal education is underpinned by the TPACK framework of Shulman's $(1987,1986)$ in describing how teacher's understanding of educational technologies and PCK interact with one another to produce effective teaching with technology. In this model, the three main components of teacher's knowledge: content, pedagogy, and technology were considered in determining the effect of Math Apps on the performance of the grade 8 students at San Cristobal National High School, the School Year 2020-2021. It is a quasi-experimental research that used pre-test and post-test and a descriptive research design in describing the level of pedagogical design and features design of math apps.

Analysis revealed that the pedagogical design as well the features Design of Math Apps were resulted to a very great extent. The level of the students' performance in Mathematics resulted in a great improvement from Developing into Proficient and Advanced stages. The test of difference between the pre-test and post-test revealed that there is a significant difference between the level of students' performance in Mathematics. Further, the study showed that Math Apps significantly affect the students' performance in the subject. Based on the results and conclusion, it is recommended that students secure different math apps since they can greatly help them improve their number intelligence; that Mathematics teachers showcase the apps and other related learning tools, and that the Department of Education strive more to address the needs of the students in this New Normal Education.
\end{abstract}

INDEX TERMS: Pedagogical Design, Feature Design, Math Apps, Mathematics Performance

\section{INTRODUCTION}

The common existence of smartphones or tablets nowadays could provide aid for better education. Through various applications that could be freely installed, learning was possible at any convenient place and time. Among the school subjects, Mathematics was one of the most difficult subjects to learn. Adding the fact that traditional face-to-face was altered to Blended Learning, approaching Mathematics would become more difficult. In this new normal education, independent learning might improve the difficulties in studying Mathematics. However, an effective tool should be introduced. The researcher thought of using Math Apps incorporated with pedagogic design to resolve the current educational needs.

In the year 2020, there were great concerns about the youth's education due to the inevitable changes caused by the COVID 19 pandemic. This matter should be given thorough attention, specifically towards the emerging vicissitudes arising from the life of students. Neglecting the needs of education would certainly affect not only the students themselves but the whole society as well. For a country with more qualitative education, that the country becomes more progressive, competitive, and productive.

The Department of Education had to alter the previous systems, aiming for the continuity of education in the middle of the existing pandemic. Such systems were made to consider the youth's education without disregarding their safety and health.

This order contained the adjustment of opening classes, specified alternative learning delivery modalities, and discussed the new school guidelines due to the emergence of COVID-19.

There could be better ways to provide education, but it must be understood that this order had to be implemented to protect the learners.

Social distancing was one of the measurements done to secure safety but hindered qualitative 


\section{EPRA International Journal of Research and Development (IJRD) \\ Volume: 6 | Issue: 7 | July 2021 \\ - Peer Reviewed Journal}

education. Conducting online classes or giving modules as a form of schooling might not be satisfying than the traditional face-to-face classes. There would be times that independent learning should be practiced with technology as a medium. Incorporate the advantages and resolve the disadvantages, the benefits of technology could ameliorate the educational crisis brought by the pandemic.

The 21 st century was the rise of technology. Rapid changes were made as technology vastly integrated into society. Access to necessary information could be achieved quicker and easier due to the burgeoning development of technology. Benefits provided by technology could make the path for the independence of learning. The method of independent learning takes learners to discover their capabilities in their ways. They could have control over their learning stage and process. As learners had individual styles to cultivate their skills and knowledge, a chance to explore would lead to the discovery of learning styles individually befitting to them.

Therefore, the researcher thought of using the benefits of Math applications to student's learning. The researcher would like to see if Math apps were indeed effective and able to give positive results in the mathematics performance of the learners.

\subsection{Objectives of the Study}

This study determined to use of math apps to the math performance of the students in New Normal Education

\section{LITERATURE REVIEW}

Integration of technology to support learning in the new normal education is necessary. Therefore, teachers should master the technological tools selected for teaching. They should be able to select the most appropriate technological tools available and accessible for everyone. A good educator has the adaptability and flexibility to resolve the educational crisis ahead, wisely using the resources and materials that can be afforded to ameliorate teaching and learning.

Analysis indicated that Apps catering to a range of age groups are represented in the top ten Apps in the 'education' section of the App Store. Data, aggregated over each of the data collection points, indicates that $29 \%$ of the Apps were designed to cater to children in before school settings, $24 \%$ for primary-aged children, and only $13 \%$ were designed for secondary education. A large proportion (34\%) were classified as 'Multi-age', which is suitable for use across a range of children. These findings reflect a similar analysis by Shuler (2012).

According to pedagogic elements and design features, various Apps can be classified. The classification was based on the coding used to analyze interactive multimedia (Goodwin, 2009; Goodwin \& Highfield, in press). There are three broad classifications of Pedagogical Designs: instructive, manipulative, and constructive.

The first Pedagogic Design, Instructive Apps, is designed with elements of 'drill-and-practice. Whereby, the Apps should contain a predetermined task and a homogeneous response is required from the user. These are designed as learner-centered Apps and the focal point is the learner's performance through providing proper instructions for learning. Apps were created not only for education but also for entertainment purposes since they target are young learners. This implies that learning should be approached in fun ways to motivate for learners.

According to Highfield and Goodwin (2013), each App was classified based on the coding used to analyze interactive multimedia. These Instructive Apps generally require a minimal cognitive investment on behalf of the learner and are frequently based on behaviorist concepts and use extrinsic rewards. "Math Bingo" by ABCya.com and "Quick Math" by Shiny Things are presented as exemplars of instructive pedagogic design. It was highlighted in the study the use of the nature of Math Apps as Instructive its popularity and beneficial among parents and students who see "drill-and-practice" mathematics learning in problem-solving tasks.

Instructional design strategies can be defined as the science of developing structured instructions and specifications in designing the teaching material to instruct learners (Martin, 2011). The instructional design stems up from the art of creating training experiences that would enable the learning to be more efficient, effective, and appealing. It is a methodology of the creation of training experiences to enable the learning more efficiently, effectively, and highly appealing (Merrill, 2012). And with digital interventions, learning can be more fun, creating a positive attitude towards a subject, encouraging creativity.

Furthermore, from the point of view of the Instructional designers, preparation and dissemination of E-material are not expensive. They can train several students, apart from maintaining quality on par with classroom training (Waldner et al., 2012). Geer et. al. (2017) report that teachers found mobile learning positively contributing to student-centered learning with pupils more in control of their learning than traditional teaching could have allowed. This allows the student to learn at their own pace, leaving teachers free to provide one-to-one support where needed and allowing more advanced pupils to move on to more challenging materials.

The second Pedagogic Design, Manipulable 


\section{EPRA International Journal of Research and Development (IJRD)}

Apps, that is designed with manipulable elements. Whereby, the Apps should contain a predetermined context or framework. While the Instructive Apps require minimal thinking, Manipulable Apps require more but not as much as the third Pedagogic Design. This App enables guided discovery and experimentation.

Active learning in math apps is fostered through the direct manipulation of virtual objects, verbal labels, and numerical representations (Lindahl \& Folkesson, 2012). Touch-screen tablets are mobile, light weight, and do not rely on dexterity-based motor skills that are needed to use a computer keyboard or mouse (Kucirkova, 2014). Math Apps with the incorporation of manipulable design and advanced technology are recognized as manipulatives. The simultaneous presentation of auditory and visual inputs engenders multisensory learning and has been shown to facilitate children's understanding (Carr, 2012; Pavio, 1986). Young students cannot think abstractly (Bruner, 1964; Carbonneau et al.,2013). However, the use of manipulatives may provide a much-needed solution for young learners who are faced with abstract concepts. Researchers have found that students who used manipulatives actively developed their understanding and bridged the gap between the abstract and concrete because they were able to visualize the mathematical concept through building models with the manipulatives. Thus, when students can use manipulatives as learning tools, they can enhance their abstract thinking ability.

According to Highfield and Goodwin (2013), each App was classified by Pedagogical Design which includes: instructive, manipulable, and constructive apps. Constructive Apps are characterized by a more open-ended design that allows the users to create content and digital artifacts. Open-ended drawing Apps are emblematic of Constructive Apps and generally do not utilize extrinsic rewards and provide the user opportunities for choice and creativity. "Explain Everything" by Morris Cooke and "My Story" by HiDef Web Solutions are examples of this pedagogical design.

Effective learning can be achieved through constructive design. According to Mugambi (2018), people construct their understanding and knowledge of the world through experiences and reflection. Knowledge is the construction of gained ideas and experiences. Knowledge is not passively received but actively built up by the cognizing subject and that function of cognition is adaptive and serves the organization of the experimental world.

The last discussion on the last pedagogical design of Math Apps is constructive. Pedagogic Design, Constructive Apps, is more open-ended. These Apps generally do not utilize extrinsic rewards and provide the user opportunities for choice and creativity. According to Highfield and Goodwin (2013), Open-ended drawing Apps are emblematic of Constructive Apps and generally do not utilize extrinsic rewards and provide the user opportunities for choice and creativity. "

Constructive designed Apps make learners construct knowledge rather than passively taking information, whereby similarly explained in the theory of Constructivism. According to Bhattacharjee (2015), Constructivism is an epistemology, or a theory, used to explain how people know what they know. Fundamentally, constructivism says that people construct their understanding and knowledge of the world through experiencing things and reflecting on those experiences. Constructivism is a theory that asserts that learning is an activity that is individual to the learner. This theory hypothesizes that individuals will try to make sense of all information that they perceive, and that everyone will, therefore, "construct" their meaning from that information.

Effective learning can be achieved through constructive design. According to Mugambi (2018), people construct their understanding and knowledge of the world through experiences and reflection. Knowledge is the construction of gained ideas and experiences. Knowledge is not passively received but actively built up by the cognizing subject and that function of cognition is adaptive and serves the organization of the experimental world.

Klimova's (2019) study illustrates that mobile apps can be effective in the enhancement of student's performance in terms of their language learning by implementing smartphone app learning in a continuous assessment. Johnson et al. (2016) found out that learning programs that use web-based teaching offer students more adaptability to learn at their own pace and at convenient times, reduced travel time, and additional opportunities for reviewing course materials.

The study concluded that the use of the mobile application in teaching mathematics to Grade 8 students in a public national high school by using the mobile application had somehow helped enhanced students' achievement and learning. In line with quality education, the administrator should enforce and include the use of the mobile application in carrying out learning to its maximum. The teacher must also equip with the latest trend for learners to become globally competitive (Etcuban \& Pantinople, 2018).

The phenomenal advances in mobile technologies and the accompanying explosions in the availability of mobile Apps have impacted almost all facets of our lives and are expected to have even wider and deeper impacts soon. The Apps are just 


\section{EPRA International Journal of Research and Development (IJRD)}

Volume: 6 | Issue: 7 | July 2021

- Peer Reviewed Journal

beginning to make inroads in the education domain.

Grane (2016) demonstrates that multimedia content is not separate from the format, but that the interaction design of the applications for mobile devices determines the accessibility of content for users, especially for pre-schooled-aged children. The quality of mobile applications targeted at early childhood thus depends on two conditions: taking into consideration the developmental stage of the child when formulating content and activities and employing an interaction design that is appropriate to the child's cognitive and psychomotor development. This interaction design presents key difficulties in the search for simplicity due to the elevated presence of distractors and active elements on the screen that are often unnecessary. Although research demonstrates the potential of quality interactive resources for learning, the apps reviewed did not adapt to the needs of the target group. It was suggested that complements the heuristics analysis with observations of the interaction of children with the apps, define a direct implication, and establish a relationship with developers to improve interactive materials and adaptability.

In recent years educational technology has long been recognized as a valuable approach in improving the mathematics achievement of elementary school according to Zhang et al (2015). Most of the studies focused on using the mobile application to provide learners with a handy and individualized game-based environment to enhance their achievement and interest in mathematics (Yeh., C. Y., Cheng, Hercy., N. \& Chan, T. W., 2019). It revealed, students engaged themselves in solving various exercises with the support of immediate feedback until they pass the requirement of every building in their Math-Island. However, the students learned mathematical concepts mainly by watching videos in the system, which provided the only demonstration like a lecturer. building in their Math-Island. However, the students learned mathematical concepts mainly by watching videos in the system, which provided the only demonstration like a lecturer. For this reason, the effect of the mobile devices' conceptual understanding was like teachers' conventional instructions.

Although there have been qualitative analyses of the use of mobile devices in education, systematics quantitative analyses of the effects of mobileintegrated education are lacking. Sung \& Liu (2016) stated that the unique features of mobile devices can enhance the essential functionalities of certain specific teaching methods, and thus promote educational teaching methods, and promote educational outcomes. The "individuality" combined with wireless communication enabled more selfpaced and self-directed study. It also resolves the difficulties of putting formative assessment in the classroom. Another feature that empowers the teaching and learning process is the portability and context awareness of mobile devices. These two features allow learners to exploit the information in the environments in which they are situated, and to retrieve, record, and react to the scores needed to resolve their learning issues by traversing multiple learning environments.

Mobile technology can offer new opportunities for learning that extend beyond the traditional teacher-led classroom scenario. Its advancement in technology in wireless has had an impact in educational settings, thus generate a new approach in teaching. Nowadays, mobile learning is the buzzword of the day. The new advances in learning via smartphones of cellular and mobile technologies now allow teachers and students to expand their undeniable potential and accessibility to learning opportunities. Furthermore, the use of mobile learning in education can change the teachers' or instructions' perception of teaching and learning Maslin, M \& Ismail, Z (2010).

Ling et al (2014) sought to understand whether the use of mobile applications had an impact on students' learning of the new statistical concept When learning through examples with the mobile app, students performed better on problems that required them to apply their knowledge, which corresponds to the third level of learning in Bloom's taxonomy.

Recent years have seen a quick expansion of tablets and Zhang et al (2015) stated that use of math apps, employed different scaffolding strategies to support the learning of decimals and multiplication. Resulted of improved student learning in mathematics and reduces the achievement gap between the two groups.

Currently, the e-learning method, due to the period of confinement that is occurring due to COVI-19, had increased its use and application in the teaching and learning processes. The main objective of this research is to identify the effectiveness of the elearning methods in the teaching of mathematics with adults who are om high school, in contrast to the traditional expository method. Furthermore, it should be considered that the e-learning methods will favor the autonomy of the student, adapting to his or her learning

\section{METHODOLOGY}

The Quasi-Experimental research design utilized in the study specifically the pre-test and posttest design where the students were randomly assigned to be part of the study. The selected grade 8 students were exposed to the use of Math Apps during their learning process in mathematics to test 


\section{EPRA International Journal of Research and Development (IJRD)}

the effect on the math performance of the students. It aims to establish a cause and effect between the independent and dependent variables. The researcher used existing groups by controlling them in the analysis. It is often used to conduct and evaluate the effectiveness of treatment.

The use of math apps to 100 grade 8 students at San Cristobal National High School during the third quarter grading of the school year 2020-2021. The students were selected through non-probability sampling, particularly through the purposive sampling procedure. Each section is composed of 20 students in each section. After grouped heterogeneously, each section was given pre-test and posttest to determine the effect of math apps in their math performance. This design is based to identify choosing respondents who will belong to use as an observable respondent who will receive scaffolding in nurturing the academic performance of the learners with the use of math app. The respondents were made to complete all the needed scales and assessments from the beginning to the end of the study.

To gather the relevant data on this study, the research instruments were constructed parallel to the design of the study. Since this research was a quasiexperimental design that focused to conduct and evaluating the effectiveness of a treatment, the following instruments were utilized.

Math apps is an educational learning tool designed to support mastery of mathematical conceptual knowledge, it is used during the learning process in mathematics, to test and determine the mean level of the math performance of the learners. It was measured using the constructed pre-test and post-test aligned to MELC, validated using the Cronbach alpha that tested the reliability of the given questions administered to the students before and after the intervention of the math apps. Survey Checklist is used to determine the mean level of the pedagogical and features the design of math apps to be evaluated by the grade 8 students at San Cristobal National High School.

The mean and standard deviation, to determine the mean level of the how high the level of the performance on pre-test and post-test in Math. The mean and standard deviation is organized according to their group. And Paired t-test was used, to determine statistically the difference in the mathematics performance between the pre-test scores and post-test scores of the students to test if there is a significant difference in the performance.

\section{RESULTS AND DISCUSSIONS}

\section{Level of Pedagogical Design of Math Apps}

Table 1 shows the summary result of level of pedagogical design of math apps in terms of instructive, manipulative and constructive.

Table 1. Level of Pedagogical Design of Math Apps

\begin{tabular}{cccc}
\hline $\begin{array}{c}\text { Pedagogical } \\
\text { Design }\end{array}$ & Mean & SD & $\begin{array}{c}\text { Verbal } \\
\text { Interpretation }\end{array}$ \\
\hline Instructive & 4.50 & 0.50 & Very Great Extent \\
Manipulative & 4.32 & 0.51 & Very Great Extent \\
Constructive & 4.34 & 0.47 & Very Great Extent \\
\hline
\end{tabular}

The overall mean $(\mathrm{M}=4.50, \mathrm{SD}=0.50)$ for the level of pedagogical design of math apps as to Instructive indicates how data scores are homogeneous to each other.

According to Merrill (2012), the instructional design of apps stems up from the art of creating training experiences that would enable the learning to be more efficient, effective, and appealing. It is a methodology of the creation of training experiences to enable learning more efficiently, effectively, and highly appealing. The mobile app aimed to support the teaching instructional for Filipino teacher educators. In a knowledge-driven enterprise, mobile learning introduces new ways for students to learn and educators to teach (Marcial, 2014). The study revealed that a mobile application is highly useful perceived by the respondents. The result implies that the respondents will assuredly accept and use the mobile tool in their classroom. It can be concluded that teacher educators will strongly adopt the proposed instructional tool and integrate it into their teaching and learning activities.

The overall mean for the level of pedagogical design of math apps as too manipulative has $(\mathrm{M}=4.32, \mathrm{SD}=0.51)$ and it indicates

students after being exposed to math apps strongly agreed to a great extent that learning with math apps sets a motivational activity that develops their abstract thinking, as well as critical and analytical thinking, are being stimulated. This implies that they are motivated to learn because of its manipulable design.

According to Highfield and Goodwin (2013), each App was classified by Pedagogical Design and was classified based on the coding used to analyse interactive multimedia. These are based on the natural structures that allow the user to manipulate elements, enabling guided discovery learning and experimentation within a pre-determined context of the framework. These Manipulable Apps require more cognitive investment than the Instructive Apps, but less than constructive Apps. Manipulable Apps 


\section{EPRA International Journal of Research and Development (IJRD)}

require the correct answer to complete a task; these mobile applications provide flexible solution strategies and/ or manipulable representation.

The simultaneous presentation of auditory and visual inputs engenders multisensory learning, and which has been shown to facilitate children's understanding (Carr, 2012, Carbonneau et al.,2013). However, the use of manipulatives may provide a much-needed solution for young learners who are faced with abstract concepts. (Carr, 2012, Carbonneau et al.,2013) found that students who used manipulatives actively developed their understanding and bridged the gap between the abstract and concrete because they were able to visualize the mathematical concept through building models with the manipulatives. Thus, when students can use manipulatives as learning tools, they can enhance their abstract thinking ability.

And lastly, the overall mean $(\mathrm{M}=4.34$, $\mathrm{SD}=0.47$ ) for the level of pedagogical design of math apps as to constructive indicates how data scores are homogeneous to each other. This implies that students are strongly agreed that Math Apps as Constructive is a Very Great Extent.

As defined by Goodwin (2013) constructive
Apps are characterized by a more open-ended design that allows the users to create content and digital artifacts. Open-ended drawing Apps are emblematic of Constructive Apps and generally do not utilize extrinsic rewards and provide the user opportunities for choice and creativity. In the absence of the traditional face to face classroom, using Math Apps, students can continuously construct their understanding and knowledge of the world through experiences and reflection since knowledge is the construction of gained ideas and experiences (Mugambi, 2018),

The study revealed that the math apps as the constructive pedagogical design develops a substantial teaching approach. The result implies that the respondents will assuredly accept and use the mobile apps in learning under this new normal education.

\section{Level of Features Design of Math Apps}

Table 2 shows the summary result of level of design features of math apps in terms of content, interaction and graphical

\begin{tabular}{cccc}
\multicolumn{3}{l}{ able 2. Level of Features Design of Math Apps } \\
\hline Feature Design & Mean & SD & $\begin{array}{c}\text { Verbal } \\
\text { Interpretation }\end{array}$ \\
\hline Content & 4.35 & 0.48 & Very Great Extent \\
Graphical & 4.41 & 0.40 & Very Great Extent \\
Interaction & 4.39 & 0.46 & Very Great Extent \\
\hline
\end{tabular}

The overall mean $(\mathrm{M}=4.35, \mathrm{SD}=0.48)$ for the level of content of design features of math apps, most of the students Strongly Agreed that Math Apps as to contain the knowledge, skills, and values are expected to learn and are aligned in Mathematics which is appropriately designed for learning Mathematics. It was also observed by the students, Math Apps approached learning very easily and conveniently. However, it was also gleaned that student Agreed that the content of Math Apps is sufficient and beneficial for their learning process. Furthermore, this implies that students are strongly agreed that Design Features of Math Apps as to Content is Very Great Extent.

According to Klimova (2019), mobile apps can be effective in enhancing the student's performance by implementing smartphone app learning in a continuous assessment. The study revealed that learning via smartphones is effective in the enhancement of student's performance. In this period of COVID pandemic crisis, students are to be learned independently, the use of the Math apps that designs students' needs and continuously facilitated by a teacher, only then can it be contributing to positive learning outcomes. In addition, the results also confirm that mobile learning can serve as an appropriate complementary method to other forms of course delivery. Also, Johnson et al. (2016) found out that learning programs that use web-based teaching offer students more adaptability to learn at their own pace and at convenient times, reduced travel time, and additional opportunities for reviewing course materials, especially in this New Normal Education system.

The overall mean $(\mathrm{M}=4.41, \mathrm{SD}=0.40)$ for the level of graphical designs features of math apps, indicates how data scores are homogeneous to each other. Furthermore, this implies that students are strongly agreed that Design Features of Math Apps as to Graphical is Very Great Extent.

Handal et al (2014) mentioned in their study apps in mobile provide structure to facilitate or scaffold the collection and presentation of data by students or groups of students. These self-contained programs are endowed with various technical and pedagogical affordances. For example, they are multimedia-based with audio, image, and/ or animation functionalities. It is like Chachil et. al. (2015) stating in his literature that respondents preferred to learn mobile apps. Mobile Apps assisted them to understand better with the help of audio (the sound of native speakers) and the sample graphical 


\section{EPRA International Journal of Research and Development (IJRD)}

illustration implemented in the application. It is also indicated that the respondents' satisfaction towards the application is high. However, further studies need to be done to enhance the design and function such as the search function that could have enabled the users for their desired phrases or words.

And lastly, the overall mean $(\mathrm{M}=4.39, \mathrm{SD}=$ 0.46 ) for the level of interaction design features of math apps indicate how data scores are homogeneous to each other. It is also observed that Math Apps, are made not to passively absorb but actively gain knowledge for these math apps are made with content to process, task to accomplish, and problems to solve.

Furthermore, this implies that students are strongly agreed that Design Features of Math Apps as Interaction is Very Great Extent. Socially interactive learning is evident in the math apps with the onscreen teacher providing demonstrations and task instructions, which children can repeat when needed
(Troseth, 2010). This can offer the efficient and effective delivery of one-to-one instruction, which is an important component of math interventions (Holmes \& Dowker, 2013).

This can help provide an efficient childcentered but scaffolded learning environment (Mayer, 2004; Mayo, 2009) tailored to individual needs (Slavin \& Lake, 2008) enabling individualized and structured instruction (Gulliford \& Miller, 2015) without additional, time consuming, teaching demands (Kucian, et al, 201; Hilton, 2016).

\section{Weekly Level of Mathematics Performance of students of pre-test and post-test}

Table 3 shows the summarize of weekly performance of the students in their pre-test and posttest scores in math.

Table 3. Weekly Level of Mathematics Performance of students of pre-test and post-test

\begin{tabular}{rcccccc}
\hline \multirow{2}{*}{ Scores } & \multicolumn{2}{c}{ PRE-TEST } & & \multicolumn{2}{c}{ POST-TEST } & \multirow{2}{*}{ Verbal Interpretation } \\
\cline { 2 - 3 } Week 1-2 & Mean & SD & Verbal Interpretation & Mean & SD & Advanced \\
Week 3-4 & 7.21 & 3.65 & $\begin{array}{l}\text { Developing } \\
\text { Proficiency }\end{array}$ & 17.83 & 2.37 & Proficient \\
Week 5-7 & 7.79 & 2.79 & $\begin{array}{l}\text { Developing } \\
\text { Proficiency }\end{array}$ & 15.52 & 3.14 & Proficient \\
\hline
\end{tabular}

As shown in table above, most of the scores obtained by the grade 8 students got a mean score of 7.21 under the scale of $5-8$ for pre-test with the verbal interpretation of Developing Proficiency in mathematics performance for the Week 1-2. The students at this stage acquire a minimum level of knowledge and core understanding about axiomatic structures of a mathematical system in Geometry, its defined terms, undefined terms, postulates, and theorems. This only indicates that the students do not acquire the knowledge and retention of the basic terms of geometry indicated in the questions unless they would be guided for them to understand. After being exposed on the use of Math Apps (Basic Geometry and Math Formula \& Practices), the grade 8 students show a good performance obtaining a remarkable result of mean scores of 17.83 under the score scales of 17-20 under the level of Advanced Proficiency.

This means that their understanding about concepts and theories has exceeds the core requirements and can transfer their understanding skills in a flexible authentic performance task in solving further Mathematical problems. It is also observed that some of the students obtained Approaching Proficiency in their mathematics performance. This indicates that the students were able to follow the correct information given that would lead them to correct responses despite the absence of the traditional face-to-face classroom approach. Students show their independent progress within weeks 1-2.

It can be gleaned, most of the scores obtained by the grade 8 students got a mean score of 7.79 under the scale of 5-8 for pre-test with the verbal interpretation of Developing Proficiency in mathematics performance for the Week 3-4. This means that the students, before the use of the Math Apps struggle with their performance that involves the illustration of triangle congruence, illustration of SAS, ASA, and SSS congruence postulates. The mathematical illustration between the congruence of SAS, SSS, and ASA is not being identified to the student's knowledge that may lead them to a correct response.

Post-test scores after being exposed to Math Apps (Khan Academy) showed Approaching Proficiency to Advanced Level where most of them show a good performance obtaining a remarkable result of mean scores of 15.52 under the score scales of 13-16 under the level of Proficient.

And lastly, most of the scores obtained by the grade 8 students got a mean score of 5.25 under the scale of 5-8 for pre-test with the verbal interpretation 


\section{EPRA International Journal of Research and Development (IJRD)}

of Developing Proficiency in mathematics performance for Week 5-7.

The students at this level struggle with their understanding of the process of solving corresponding parts of congruent triangles, proving two triangles are congruent and proving statement on triangle congruence. There is a minimal number of students who can reach Approaching Proficiency. The students on this level have minimum knowledge and skills on executing the lesson to arrive at a correct response to the problem.

After the students used the Math Apps, their post-test scores Proficiency reach Approaching to Proficient. It can be shown that most of the students got Approaching where most of them show a good performance obtaining a remarkable result of mean scores of 15.58 under the score scales of 13-16 under the level of Proficient which indicates that half of the students have at least furnished their mathematics performance, skills and core understanding in solving mathematical problems.

To explain further, studies showed a positive effect of mobile learning applications on students' academic achievement. The studies show that mobile learning promotes students' academic achievement. Additionally, the students appreciated mobile learning as an approach that may significantly increase their motivation. Researchers and practitioners should take into consideration that mobile learning can create a positive impact on academic achievement and performance and increase the motivation of students (Demir and Akpinar, 2018).

The collaborative of the pedagogical design of the Math Apps helped the students achieved the competency as well as discover the features of the design of Math Apps that helps them to obtain the correct response. Moreover, math apps give them sets of examples for them to better understand the triangle congruence with provided video lessons and short quiz as an opportunity for them to integrate their acquired knowledge and skills.

Learning through examples with the mobile app, students performed better on problems that required them to apply their knowledge, which corresponds to the third level of learning in Bloom's taxonomy. It showed that students in the app group felt strongly that mobile apps helped them understand the new concepts more clearly and were more confident in their ability to learn the new material more quickly than the control group. Overall, it demonstrates that incorporating mobile apps into lectures has the potential to positively affect student learning (Ling, 2014).

Test of Difference between the Pre-test and Post-test of Mathematics Performance of the students.

Table 4. Test of Difference between the Pre-test and Post-test of Mathematics Performance of the students.

\begin{tabular}{cccccccc}
\hline Week & Groups & Mean & SD & t & Sig. & $\begin{array}{c}\text { Mean } \\
\text { Diff. }\end{array}$ & Interpretation \\
\hline \multirow{2}{*}{ Week 1-2 } & Pre-test & 7.21 & 3.65 & -28.43 & 0.000 & -10.62 & Significant \\
& Post-test & 17.83 & 2.37 & & & & \\
Week 3-4 & Pre-test & 7.79 & 2.96 & -24.35 & 0.000 & -7.73 & Significant \\
& Post-test & 15.52 & 3.14 & & & & \\
Week 5-7 & Pre-test & 5.25 & 2.43 & -40.82 & 0.000 & -10.33 & Significant \\
\hline
\end{tabular}

The test of the difference between the pre-test and post-test of mathematics performance of the grade 8 students shows a computed value of $(\mathrm{t}$-value $=-28.43$; $\mathrm{p}<.05)$ for weeks $1-2$ interpreted as Significant.

The second test of the difference between the pre-test and post-test of mathematics performance of the grade 8 students shows a computed value of $(\mathrm{t}-\mathrm{value}=-24.35 ; \mathrm{p}<.001)$ for week $3-4$ with verbal interpretation of Significant.

And lastly, the test of the difference between the pre-test and post-test of mathematics performance of the grade 8 students shows a computed value of $(\mathrm{t}-$ value $=-40.82 ; \mathrm{p}<.001)$ for week $5-7$ with the verbal interpretation of Significant.

Based on the data, it is shown that there is a significant difference between pre-test and post-test math scores of students using Math Apps at 0.05 level of significance. It shows that there is a significant difference in the Mathematics Performance in terms of pre-test and post-test.

Most of the studies reveal that mobile application provides learners with a handy and individualized game-based environment to enhance their achievement and interest in mathematics like (Yeh et al, 2019). It revealed that students engaged themselves in solving various exercises with the support of immediate feedback until they pass the requirement of every building in their Math-Island. Sung \& Liu (2016) stated that the unique features of mobile devices can enhance the essential functionalities of certain specific teaching methods, and thus promote educational teaching methods, and promote educational outcomes that resulted in students becoming globally competitive.

Mobile applications offer new opportunities for learning that extend beyond the traditional 


\section{EPRA International Journal of Research and Development (IJRD)}

teacher-led classroom scenario. Its advancement in technology in wireless has had an impact in educational settings, thus generate a new approach in teaching. Furthermore, the use of mobile learning in education can change the teachers' or instructions' perception of teaching and learn (Maslin et al., (2010).

\section{CONCLUSIONS AND RECOMMENDATIONS}

Based on the finding of the study, the following conclusions were drawn:

The level of the Pedagogical Design, as well as the Design Features of Math Apps, resulted in a Very Great Extent to the students.

The test of the difference between the pre-test and post-test of the respondents resulted that rejecting the null hypothesis. This implies that there is a significant difference in the level of the mathematics performance. Moreover, it shows how Math Apps is a significantly improved students' acquired skills and knowledge that significantly affect the Mathematics Performance of the students in this New Normal Education.

The following were the recommendations based on the above - mentioned findings:

1. Through the finding of this study, students may spend their time gathering different math apps that may best help them in learning mathematics especially in this new normal education where you are to learn independently. The use of Math Apps may help the students to support their independent learning so that there will no gap during the learning process.

2. The findings of the study would create an opportunity to integrate Math Apps with design features mentioned in the study. To provide the best tools that support their learning process during new normal education. Math Apps should be also aligned to the compressed MELC competencies so that students may be able to acquire the expected knowledge, skills, and values expected of them.

3. The findings of the study encourage to create an opportunity to extend the continual learning of the students by giving webinars about Math Apps to the teachers in key areas which would help the students to learn despite this new normal education where students are learning independently.

4. Since the study found out that there is an improvement in the math performance of the students, the teacher may also use and find different math apps that can be paired in their selected learning competency targets. With the use of Math Apps, teachers can improve the No Left Behind System of DepEd.

5. The Department of Educations can share the result of the study with all teachers in the public and private sector for an innovative learning mobile approach. It can also be one of the topics worth sharing on series of webinars in ensuring the learning quality to the students. Also, this would be one of the responses to upgrade the proposal math apps that are aligned to the MELC in this new normal education. Furthermore, a collaboration with DOST and DICT to promote and developed apps such as Courseware should be given emphasize for it is truly applicable in these no face-to-face classroom instructions.

\section{ACKNOWLEDGEMENT}

The author of this research would like to extend his acknowledgement to the great opportunities, pathway, and great consideration of all concerned personnel, professionals, and stakeholders of Laguna State Polytechnic University, Santa Cruz Main Campus including the president, Dr. Mario R. Briones, the dean of the college of teacher education, Dr. Florhaida V. Pamatmat, the chairperson for research and development, Dr. Benjamin O. Arjona, the thesis adviser, Dr. Evelyn A. Sunico, the internal and external subject specialists, Dr. Merilyn P. Juacalla and Dr. Nilda San Miguel, the internal and external mathematicians, Mrs. Marie Ann Gonzales. Also, a great gratitude for the English grammar language critique, Dr. Nimfa G. Dimaculangan, and the Grade 8 students in San Cristobal National High Schol.

\section{REFERENCES}

1. Adeninyi, V. (2011). Studying to Pass: Implication for students. Lagos. Macmillan (Books).

2. Andang Suhendi and Purwarno, (2018), Constructivist learning theory: the contribution to foreign language learning and teaching. The 1st Annual International Conference on Language and Literature, KnE Social Sciences \& Humanities. 87-95.

3. APPG. (2014). Maths and numeracy in the early years. London, UK: All Party Parliamentary Group for Maths \& Numeracy.

4. Burgstahler, S. (2012). Universal design in education: principles and applications. Washington, DC: DO-IT.

5. Disch, J. (2012). Patient-centered care/studentcentered learning. Nursing Outlook, 60, 340.

6. Disch, J. (2012). Patient-centered care/studentcentered learning. Nursing Outlook, 60, 340.

7. Gray, P. (2015). Free to learn: Why unleashing the instinct to play will make our children happier, more self-reliant, and better students for life. New York, NY: Basic Books.

8. Giridharan, B. (2012). Engendering constructivist learning in tertiary teaching. USChina Education Review 733-739.

9. Grande, M. \& Lanna, L. (2016). An analysis of the interaction design of the best educational apps for children aged zero to eight. Comunicar, 


\section{EPRA International Journal of Research and Development (IJRD)}

$n^{\circ} 46$, v. XXIV, 2016 | Media Education Journal | ISSN: 1134-3478; e-ISSN: 1988-3293

10. Hirsh-Pasek, K., Zosh, J. M., Golinkoff, R. M., Gray, J. H., Robb, M. B., \& Kaufman, J. (2015). Putting education in "educational" apps: lessons from the science of learning. Psychological Science in the Public Interest, 16, 3-34.

11. Johnson, L., Becker, S. A., Cummins, M., Estrada, V., Freeman, A., \& Hall, C. (2016). NMC horizon report: 2016 higher education edition (pp. 1-50). The New Media Consortium

12. Jonassen, D. H., \& Grabowski, B. L. (2012). Handbook of individual differences

13. learning and instruction. Routledge.

14. Mayer, R. E. (2004). Should there be a threestrikes rule against pure discovery learning? The case for guided methods of instruction. American Psychologist, 59 , 14-19. http://dx.doi.org/10.1037/0003-066X.59.1.14

15. Merrill, M. D. (2012). First principles of instruction. New York, NY: John Wiley \& Sons.

16. Morrison, G. R., Ross, S. M., Kemp, J. E., \& Kalman, H. (2010). Designing effective instruction (6th Edition.). Columbus, Ohio: John Wiley \& Sons.

17. Shuler, C. (2012). Learn, An Analysis of the Education Category of the iTunes App Store. New York: The Joan Ganz Cooney Center at Sesame Workshop.

18. Teodorescu, A. (2015). Mobile learning and its impact on business English learning. Procedia Soc. Behav. Sci.,180, 1535-1540.

19. Troseth, G. L. (2010). Is it life or is it Memorex? Video as a representation of reality. Developmental Review, 30, 155-175. http://dx.doi.org/10.1016/j.dr.2010.03.007

20. Enhance Academic Outcomes of students with Special Needs. Universal Journal of Educational Research. Pp. 392-398. ISSN-2332-3205.

21. Amineh, R.J., \& Davatgari,, A. (2015). Review of Constructivism and Social Constructivism. Journal of Social Sciences, Literature and Languages. Vol. 1, pp. 9-16

22. Barendregt, W., Lindström, B., Rietz-Leppänen, E., Holgersson, I., \& Ottosson, T.: Development and evaluation of Fingu: a mathematics iPad game using multi-touch interaction. In Proceedings of the 11th International Conference on Interaction Design and Children, pp 204-207. ACM.(2012) 2307096.2307126

23. Bhattacharjee, J. (2015). Constructivist approach to learning. International Research Journal of Interdisciplinary \& Multidisciplinary Studies. 65.

24. Bitter, G. \& Corral, A. (2015). Analysis of learning outcomes from mobile mathematics applications. International Journal for Innovation Education and Research. Vol. 3-3.

25. Camilleri, A.C. \& Camilleri, M.A. (2019). Mobile Learning via Educational Apps: An Interpretative Study. In Shun-Wing N.G., Fun, T.S. \& Shi, Y. (Eds.) 5th International
Conference on Education and Training Technologies

26. (ICETT 2019).

27. Carbonneau, K. K., Marley, S. M., \& Selig, J. P. (2013). A meta-analysis of the efficacy of teaching mathematics with concrete manipulatives. Journal of Educational Psychology, 105(2), 380-400.

28. Carr, J. (2012). Does Maths achievement h'APP'en when iPads and gamebased learning are incorporated into fifth-grade mathematics instruction? Journal of Information Technology Education, $11, \quad 269-286 . \quad$ http://dx .doi.org/10.28945/1725

29. Chachil, K., Engkamat, A., Sarkawi, A., Awang R. (2015). Interactive multimedia-based mobile application for learning iban language (IMMAPS for Learning Iban Language). ProcediaSocial Behavior Sciences. 167 (2015) 276-273.

30. Chary, V. R. (2014). TELEMODE-A proposal towards technology enhanced learning, engineered with mobile devices. Procedia Computer Science. Social Behavior. 34(2014) 583-586

31. Drigas, A. \& Pappas, M. (2015). A review of mobile learning applications for mathematics. International Journal of Interactive Mobile Technologies.

32. Duijzer, C. A. C. G., Shayan, S., Bakker, A., Van der Schaaf, M. F., \&

33. Abrahamson, D. (2017). Touchscreen tablets: coordinating action and perception for mathematical cognition. Frontiers in Psychology, 8,144 .

34. Ergün, E. (2017). The use of graphic design in interior spaces with the effect of math. EURASIA Journal of Mathematics, Science and Technology Education.

35. Etcuban, J. \& Pantinople, L. (2018). The effects of mobile application in teaching high school. International Electronic Journal of Mathematics Education e-ISSN: 1306-3030. 2018, Vol. 13, No. 3, 249-259.

36. Fabian, K., Topping, K. \& Barron, I. (2018). Using mobile technologies for mathematics: effects on student attitudes and achievement. Education Tech Research Dev.

37. Fuchs, L. S., Fuchs, D., Compton, D. L., Powell, S. R., Seethaler, P. M., Capizzi, A. M., Fletcher, J. M. (2016). The cognitive correlates of thirdgrade skill in arithmetic, algorithmic computation, and arithmetic word problems. Journal of Educational Psychology, 98, 29 - 43. http:// dx.doi.org/10.1037/0022-0663.98.1.29

38. Geer, R., White, B., Zeegers, Y., Au, W. \& Barnes, A., 2016. Emerging pedagogies for the use of iPads in schools. British Journal of Educational Technology, 48(2). pp. 490-498

39. Guerrero, A. et al (2020). E-Learning in the Teaching of Mathematics: An Educational Experience in Adult High School. Active Methodologies for the Promotion of Mathematical Learning. 8(5), 840; 


\section{EPRA International Journal of Research and Development (IJRD)}

https://doi.org/10.3390/math8050840

40. Gulliford, A., \& Miller, A. (2015). Raising educational achievement: What can Instructional Psychology contribute? In N. Frederickson, A. Miller, \& T. Cline (Eds.), Educational Psychology Topics in Applied Psychology (pp. 83-108). Hove, UK: Taylor \& Francis.

41. Handal, B. Campbell, C., Cavanagh, M. \& Dave, K. (2014). Appraising mobile math apps: the TPACK model. ACES2014. 15th Australian Computer Education Conference. Volume 169187.

42. Highfield, Kate and Goodwin, Kristy (2013). Apps for mathematics learning: a review of educational apps from the iTunes app store. Mathematics Education Research Group of Australasia Inc. Melbourne, VIC: MERGA.

43. Hilton, A. (2016). Engaging primary school students in Mathematics: Can iPads make a difference? International Journal of Science and Mathematics Education. Advance online publication.

44. Hoang, T. V., \& Caverly, D. C. (2013). Techtalk: mobile apps and college mathematics. Journal of Developmental Education. 30-31.

45. Holmes, W., \& Dowker, A. (2013). Catch up numeracy: A targeted intervention for children who are low attaining in mathematics. Research in Mathematics Education, 15, 249-265.

46. Istiandaru, A., Istihapsari, V., Prahmana, R. C. I., Setyawan, F. \& Hendroanto, A. (2017). Characteristics of manipulative in mathematics laboratory. Journal of Physics. Conf. Series 943 (2017) 012023.

47. Kiger, D., Herro, D., \& Prunty, D.:Examining the influence of a mobile learning intervention on third grade math achievement. Journal of Research on Technology in Education, 45(1). pp.61-82.(2012)

http://dx.doi.org/10.1080/15391523.2012.107825 97

48. Kirschner, P. A., Sweller, J., \& Clark, R. E. (2006). Why minimal guidance during instruction does not work: An analysis of the failure of constructivist, discovery, problem-based, experiential, and inquiry-based teaching. Educational Psychologist, 41, 75-86.

49. Lindahl, M. G., \& Folkesson, A. M. (2012). ICT in preschool: Friend or foe? The significance of norms in a changing practice. International Journal of Early Years Education, 20, 422- 436.

50. Lin, M.-H., Chen, H.-G., \& Liu, K.-S. (2017). A Study of the Effects of Digital

51. Learning on Learning Motivation and Learning Outcome. Eurasia Journal of Mathematics, Science and Technology Education, 13(7), 35533564.

52. Ozel, S. et. Al., (2014). Effectiveness of an Online Manipulative Tool and Student's Technology Acceptance. International Journal of Educational Studies in Mathematics, 2014, 1(1), 1-15. ISSN: 2148-5984

53. Marcial, D. E. (2014). ICT in Teacher Education in Region 7. Technical Report to the Commission on Higher Education-Philippine Higher Education Research Network, Silliman University, College of Computer Studies, Dumaguete City.

54. Martin, F. (2011). Instructional design and the importance of instructional alignment. Community College Journal of Research and Practice, 35(12), 955-972.

55. Maslin, M. \& Ismail, Z. (2010). Benefits and Barriers to the Use of Mobile Learning in Education: Review of Literature. Mobile Learning: Pilot Projects and Initiatives. Informing Science Press. pp. 9-26.

56. Mugambi, M. M. (2018). Linking constructivism theory to classroom practice. International Journal of Humanities Social Sciences and Education. 96.

57. Naismith, L., Lonsdale, P., Vavoula, G., \& Sharples, M. (2004). 'Mobile technologies and learning' in futurelab literature review series. Report No. 11, Futurelab.

58. Ochkov, V. F. and Bogomolova, E. P. "Teaching Mathematics with Mathematical Software," Journal of Humanistic Mathematics, Volume 5 Issue 1 (January 2015), pages 265-285. DOI: 10.5642/jhummath.201501.15.

59. Ozdaml, F. \& Ozdal, H. (2018). Developing an instructional design for the design of infographics and the evaluation of infographic usage in teaching based on teacher and student opinions. EURASIA Journal of Mathematics, Science and Technology Education.

60. Park, Y. (2011). A pedagogical framework for mobile learning: Categorizing educational applications of mobile technologies into four types. The International Review of Research in Open and Distributed Learning, 12(2), 78-102. https://doi.org/10.19173/irrodl.v12i2.791

61. Pitchford, N. J. (2015). Development of early mathematical skills with a tablet intervention: A randomized control trial in Malawi. Frontiers in Psychology, 6, 485.

62. Ru, G., \& Ming, C. (2014). Infographics applied in design education. Workshopon Advanced Research and Technology in Industry Applications (WARTIA), Ottawa Convention Centre, Ottawa, ON, Canada, 29-30.

63. Schacter, J., \& Jo, B. (2016). Improving lowincome pre-schoolers mathematics achievement with Math Shelf, a preschool tablet computer curriculum. Computers in Human Behavior, 55, 223-229. http://dx.doi .org/10.1016/j.chb.2015.09.013

64. Serkan Ozel, S., Zeynep Ebrar Yetkiner Ozel, Z. E. Y., \& Cifuentes, L. (2014). Effectiveness of an online manipulative tool and students' technology acceptances. International Journal of Educational Studies in Mathematics, 2014, 1 (1), 1-15.

65. Slavin, R. E., \& Lake, C. (2008). Effective programs in elementary mathematics: A bestevidence synthesis. Review of Educational 


\section{EPRA International Journal of Research and Development (IJRD)}

Research,

78

http://dx.doi.org/10.3102/0034654308317473

66. Subramany, S.R. \& Farahani, A. (2012). Pointof-view article on: design of a smartphone app for learning concepts in mathematics and engineering. International Journal of Innovation Science Volume $4 \cdot$ Number 3

67. Sulistyaningsih, D.\& Aziz, A., (2019). Development of learning design for mathematics manipulatives learning based on e-learning and character building. International Electronic Journal of Mathematics Education e-ISSN: 13063030. 2019, Vol. 14, No. 1, 197-205. https://doi.org/10.29333/iejme/3996

68. Traxler, J. (2009). Learning in a Mobile Age. International Journal of Mobile and Blended Learning 1(1): $1-12$. DOI: 10.4018/jmbl.2009010101

69. Uyan, D. B. I. (2014). Data visualization and infographics in visual communication design education at the age of information. Journal of Arts and Humanities, 3(5), 39-50.

70. Waldner, L. S., McGorry, S. Y., \& Widener, M. C. (2012). E-service- learning: The evolution of service-learning to engage a growing online student population. Journal of Higher Education Outreach and Engagement, 16, 123-150.

71. Yildirim, S., Yildirim, G., Celik, E., \& Aydin, M. (2014). Student opinions about infographics design process. Journal of Research in Education and Teaching, 3(4), 247-255.

72. Zhang, Y. A. (2015a). Characteristics of Mobile Teaching and Learning. In Y. A. Zhang (Eds.). Handbook of mobile teaching and learning (pp. 11-25). Heidelberg: VS Springer.

73. Zhang, Y. A. (2015b). Design of Mobile Teaching and Learning in Higher Education: Introduction. In Y. A. Zhang (Eds.). Handbook of mobile teaching and learning (pp. 3-10). Heidelberg: VS Springer

74. Chatterjee, D. (2016). The Effect of Time Pressure on Creative Performance: Role of Intellect \& Affect. Michigan State University. Psychology-Master of Arts.

75. Blum-Ross, A., \& Livingstone, S. (2016). Families and screen time: Current advice and emerging research. Media Policy Brief 17. London, UK: Media Policy Project, London School of Economics and Political Science.

76. Calder, N. (2016). 'Makes learning easierthey're active' using apps in early years mathematics. In N. Kucirkova \& G. Falloon (Eds.), Apps, technology, and younger learners. International evidence for teaching ( $p p$. 135146). London, UK: Routledge.

77. Seoul, South Korea (May, 2019). International Economics Development and Research Center (IEDRC).

78. Çelik, A. (2012). The effect of QR code assisted mobile learning environment on productive vocabulary learning in foreign language studies and student reviews: The example of Mobile Dictionary] (Unpublished Master's thesis,
Graduate School of Educational Sciences). Gazi University, Ankara

79. Davis, K. (2012). The Effects of technology instruction on the academic achievement of fifth grade students. Unpublished Master's thesis, Graduate School of Liberty University. Lynchburg, Virginia.

80. Karthik, B., Chandrasekhar, B., David, D., \& Kumar, D. (2019). Identification of instructional design strategies for an effective e-learning experience. The Qualitative Report. 24(7). 1537$1555 . \quad$ https://doi.org/10.46743/2160$3715 / 2019.3870$

81. Klimova, B. (2019). Impact of mobile learning on students' achievement results. Department of Applied Linguistic, Faculty of Informatics and Management. University of Hradec Králové

82. Kucian, K., Grond, U., Rotzer, S., Henzi, B., Schönmann, C., Plangger, F., von Aster, M.(2011). Mental number line training in children with developmental dyscalculia. NeuroImage, $\quad 57, \quad 782-795$. http://dx.doi.org/10.1016/j.neuroimage.2011.01.0 70

83. Kwon, H. \& Capraro, M. (2018). The effects of using manipulatives on students' learning in problem posing: the instructors' perspectives. Journal of Mathematics Education

84. Roberts, N., \& Vänskä, R. :Challenging assumptions: mobile learning for mathematics project in South Africa. Distance Education, 32(2),pp.243-259.(2011).

85. Zaranis, N., Kalogiannakis, M., \& Papadakis, S.: Using mobile devices for teaching realistic mathematics in kindergarten education. Creative Education, 4(07), 1. pp.1-10. (2013). 